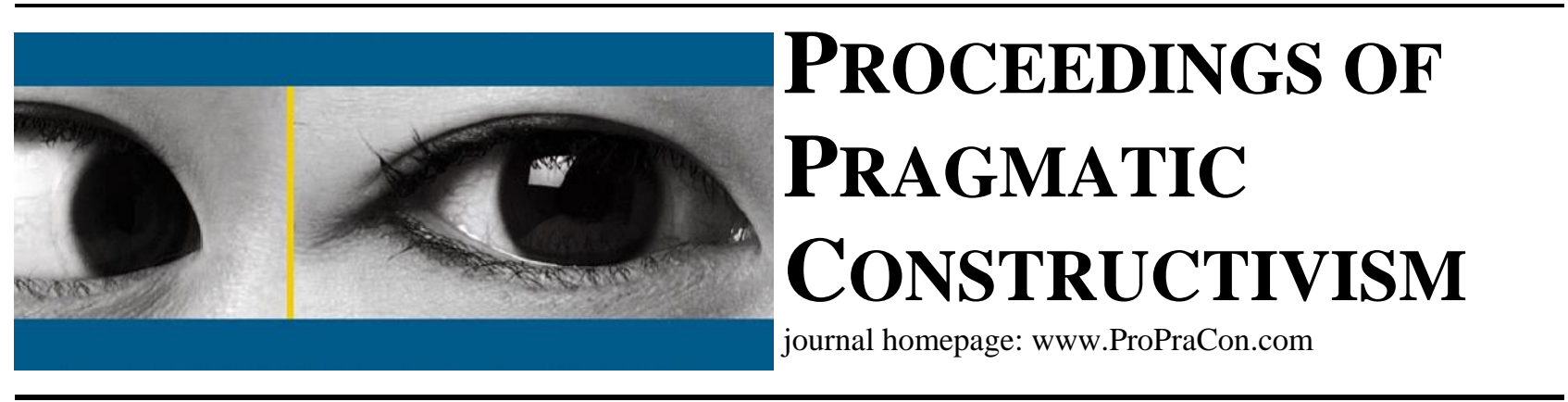

\title{
Actor-based management and captive shared services: a model for creative governance in the SME sector?
}

\author{
Will Seal \\ Professor of Management Accounting \\ Loughborough University; Centre for Global Sourcing and Services \\ Leicestershire, LE11 3TU; United Kingdom; w.b.seal@lboro.ac.uk \\ Ian Herbert \\ Senior Lecturer in Accounting and Financial Management \\ Loughborough University; Centre for Global Sourcing and Services \\ Leicestershire, LE11 3TU; United Kingdom; i.p.herbert@lboro.ac.uk
}

\begin{abstract}
This paper was presented at the 3rd Actor-reality conference, Aarhus University, October 23-25, 2013.
\end{abstract}

Keywords: Actor-reality management; shared services; SME. 
$3^{\text {rd }}$ Actor-reality conference, Aarhus University, October 23-25, 2013

\title{
Actor-reality management and captive shared services:
}

\author{
a model for creative \\ governance in the SME sector?
}

\section{Main claims to novelty}

- empirical focus - longitudinal case study of how a small but growing service firm used the shared service concept as part of its growth and internationalisation strategy.

- theoretical and methodological approach actor-reality approach (Nørreklit, 2011)

- Actor-reality approach is used to interpret case but also identify a form of creative governance for SME 


\section{Why actor-reality/actor-based research?}

- Actor-based research- creates business knowledge (Arbnor and Bjerke, 2009)

- Business knowledge is basis for value creation and capture...

- ...hence actor-reality management is a prescription for creative governance (Norreklit, 2011)

- The validity of governance model depends on its reality as defined by pragmatic constructivism (PC)

Principles of Actor based management (ABM) from Cinquini et al., (2013)

- Strategic concept: both a resource approach and a market-driven approach.. but an 'inside-out' perspective

- design process is initiated from the top.... but ' $\ldots$ the interaction between the various (groups) of employees involved takes place as dialogues.' Cinquini et al, 2013, p. 365.

- Importance of dialogue...for creativity and validity testing

- Motivation... intrinsic but extrinsic motivation (driven by reward and rule following) also plays a role

- Rooted in pragmatic constructivism (PC)... 


\section{PC: a multi-dimensional concept of reality}

- Reality establishes distinction between real and not real: fictions, dreams, illusions, hallucinations, myths and fantasies

- reality is some kind of relation between the actorwhether a person or even an organization-and the world

- the relation has to be constructed, and the construction may be faulty.

- human beings may construct this relation successfully, i.e. they create reality, by integrating elements from four dimensions: factual, logical, values and communication

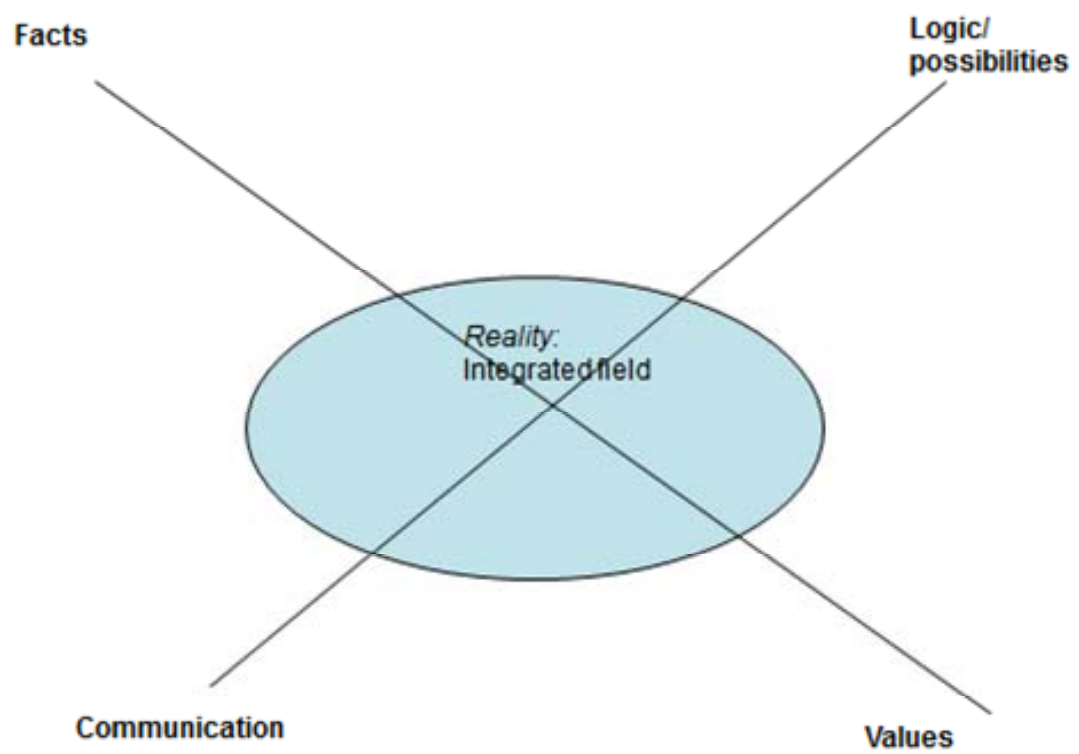

Figure 1. The construction of a management control topoi (adapted from Nørreklit, et al. 2006) 


\section{Actor-reality management and a} valid/creative organizational topoi

- business specific concepts must be created, that characterises the qualities and endeavours of the company - the managerial topoi (Norreklit, 2011).

- Actor-based leadership requires co-authorship from employees and other stakeholders (p.13).

- creative governance does not imply organizational anarchy

- To co-author a good business script, the actors need guidelines - need the lead stories

\section{Actor-reality approach to shared service organizations (SSOs)}

- actor-reality approach argues that the success of a particular form of management control depends on the extent to which it is based on reality rather than on illusions of control.

- actor-reality approach potentially challenges models such as the SSO if those models are used as a top-down, mechanistic form of governance (Seddon, 2005)

- Offers guidance for creative governance... 


\section{Creative governance in this paper}

Issues to be addressed empirically:

- Business specific topos

- Bottom up/actor based management

- Practical validity based on PC criteria

- End-to-end process orientation

Issues requiring more conceptual elaboration:

- Dialectical thinking/action

- Ex ante lean

Dialectics as logic and action: learning and creativity

- In dialectics, organizations seen as evolving/transforming..organizing as a process

- actors may use dialogue and dialectical methods as a way of reflecting on their actions - creativity is based on the notion of synthesis which emerges as a result of the dialectical relations.

- Lourenco and Glidewell (1975) stress the creativity associated with synthesis/resolution which 'entails a creativity which is contingent upon some perceptual, conceptual, or empirical reorganization by both the organization and its members' (p.. 491).

- For SSOs, conflicts may be central v local issues/customisation v standardization/authority v. empowerment... 


\section{Lean and SSOs: mixed views}

- Seddon looks at the SSO in the context of lean production, Taylorism and systems theory.

- shared service managers 'know about volumes and activity but little or nothing about the real nature of the work' (Seddon, 2005, p. 29). I

- design of the work process into front office/back office, or primary/support activities inevitably fragments the cohesiveness of end-to-end processes, leading to 'failure demand'

\section{Consultants and lean}

- some consultants/practitioners use lean rhetoric in connection with SSOs

- Difference may be explained by ex ante and ex post lean

- Ex ante lean- look at whole work process before committing to $\mathrm{SSO}$ (Seddon)

- Ex post lean- how do we make SSO work better? 


\section{A summary of the model}

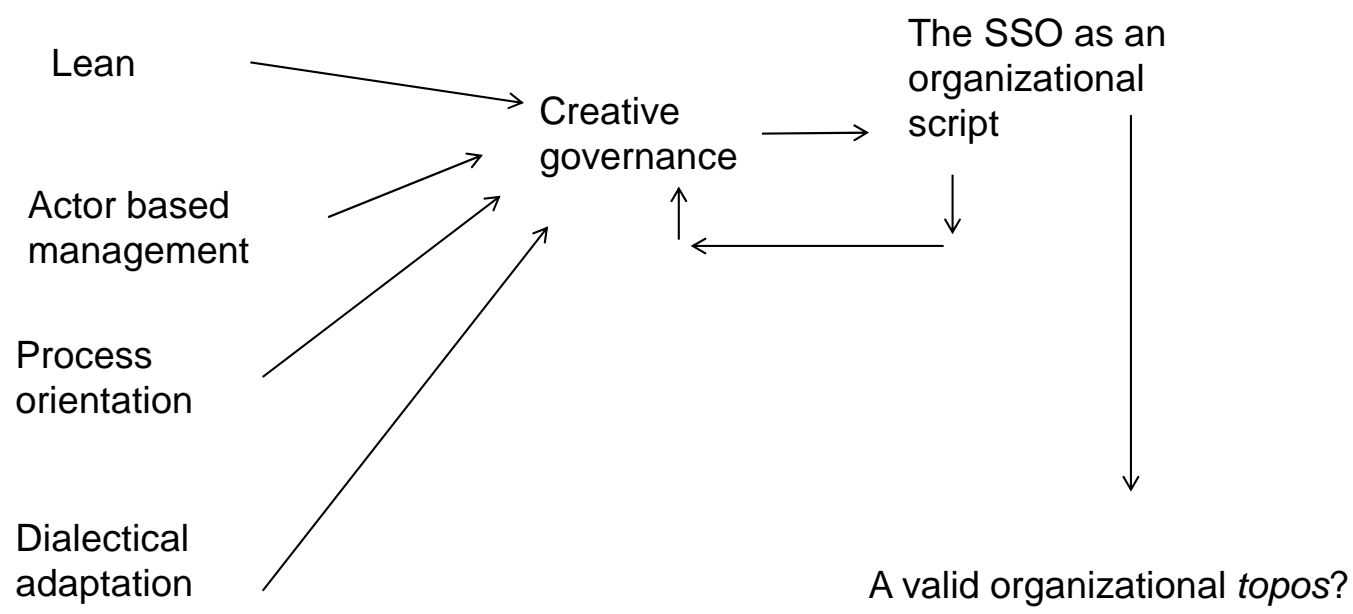

Figure 2. Some elements underpinning the SSO as a creative governance model

\section{Concepts and logics of the generic} captive SSO

- Ex ante mass production logicseconomies of scale and scope/standardisation/separation of work and thinking/command and control

- Customer focus/SLAs

- End-to-end process

- Ex post lean? 


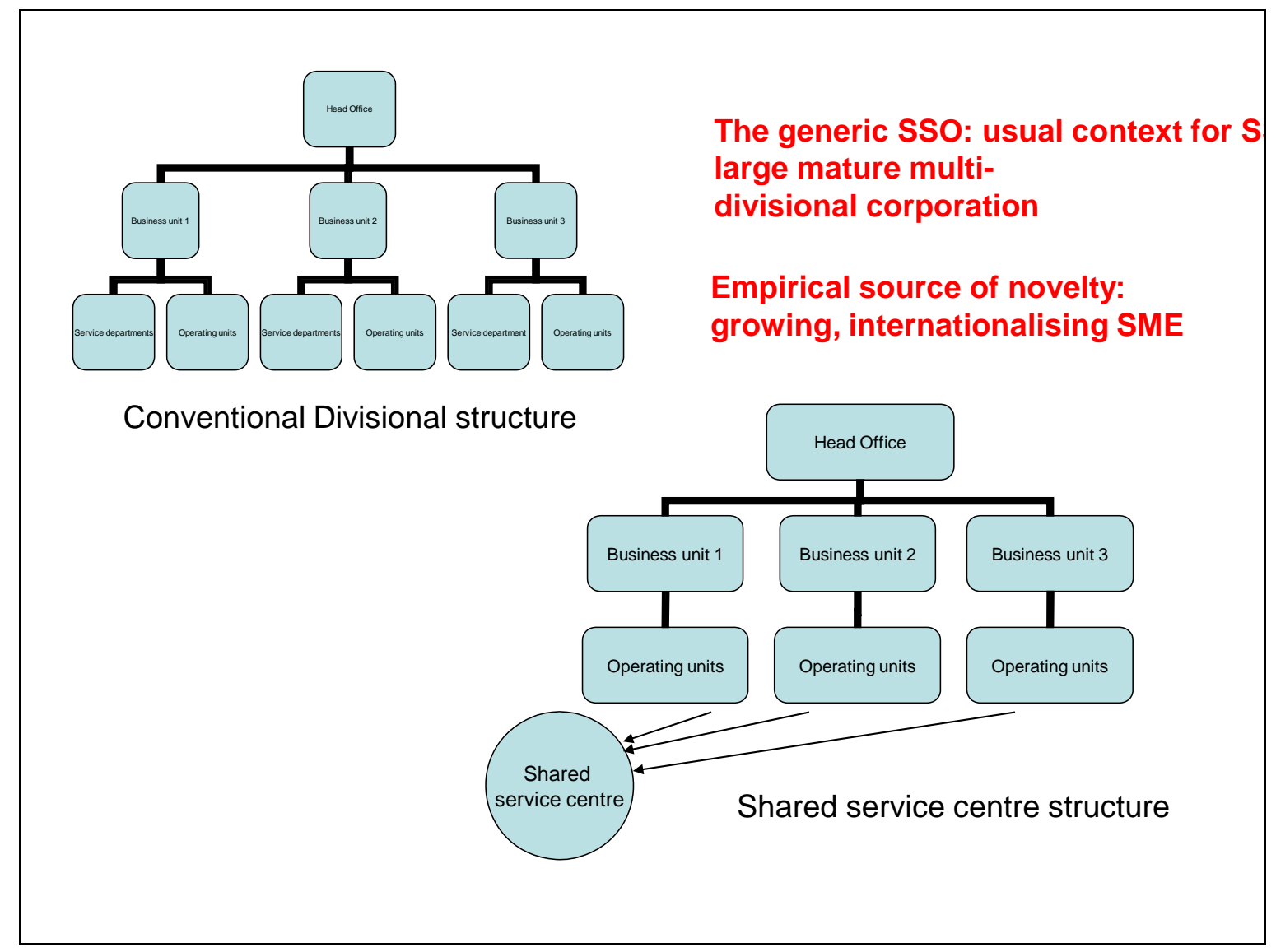

\section{From criticism to creative SSO}

- SSO literature suggests that the organizational topos associated with the SSO is quite mechanical in its ethos.

- advocates stress the benefits of standardisation and economies of scale and scope which suggests a top-down approach to management.

- critics argue that the SSO as it is usually constituted is a symptom of a wider 'command and control' management philosophy (Seddon, 2005). 


\section{The case: how do SMEs usually source support services?}

- expected that the small and medium sized enterprise (SME) will struggle to provide sufficient scale or expertise for in-house service provision let alone a multi-function SSO.

- support services are usually provided by either outsourcing (Klass, 2003) or through some form of incubator model (Allen and McCluskey, 1990).

\section{Trainco: operational director's summary}

- 'Trainco was originally set-up on its own in 1994 and became the subject of a management buyout in 1996 and remained owned by the directors and employees right through to 2011 when we were acquired by the multi-national construction and engineering group----------. So we've gone from big to small to a bit bigger to huge in about 20 years. During that time the original 99 permanent employees grew to 600 with another 200 associates around the world. Around 60 people within that have some sort of shared service responsibility, some full time and some have part responsibility' 


\section{Motives for the SSO}

- Cost... it hasn't been the primary motivator, it's been about providing a level of integrated support to the different offices around the world.

- I think the absolute key thing is that the shared services model allows the new offices to concentrate on those things which we need them to concentrate on, having the best management information service...We want the operational teams to be out there selling, recruiting and developing the business...

\section{SSO or Head Office?:}

- initially, the SSO was provided from within the Head Office $(\mathrm{HO})$ and the resources of the largest division (UK) but, over time, $\mathrm{HO}$ has taken over more of the work as the proportion that the UK comprises of the whole company has steadily reduced. The provision of services is also divided between the staff reporting centrally and activities under the control of the largest business unit.

- However, whilst the system is complex it does seem to work. That is because the objective seems to be integration and unity, rather than process expediency through standardisation at lower cost. 


\section{The creative use of service level agreements}

- We do spend a good bit of time upfront with each office each year working through the SLAs. There are 12 service activities, e.g. finance and HR to marketing and safety consultants and there are basically three service levels, gold, silver and bronze.

- There is often lengthy negotiations around who will do what in each country and thus what the recharge will be.

- If we did have to get them out of the drawer during the year it would probably mean that the service had failed...

- we actually use SLAs as much as scoping and governance documents than as performance monitoring devices.

\section{Shared Service Organisation}

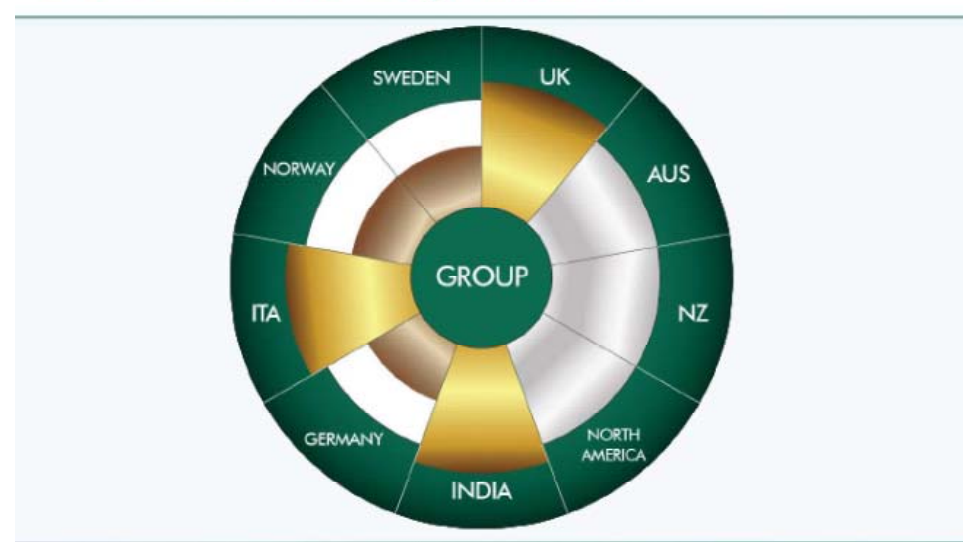

Figure 3. Levels of Support Service provided by country 


\section{Trainco: an example of creative governance?}

- Was the governance model Lean?

- Was the governance model actor-based?

- Was the governance model process oriented?

- Was the governance model dialectical?

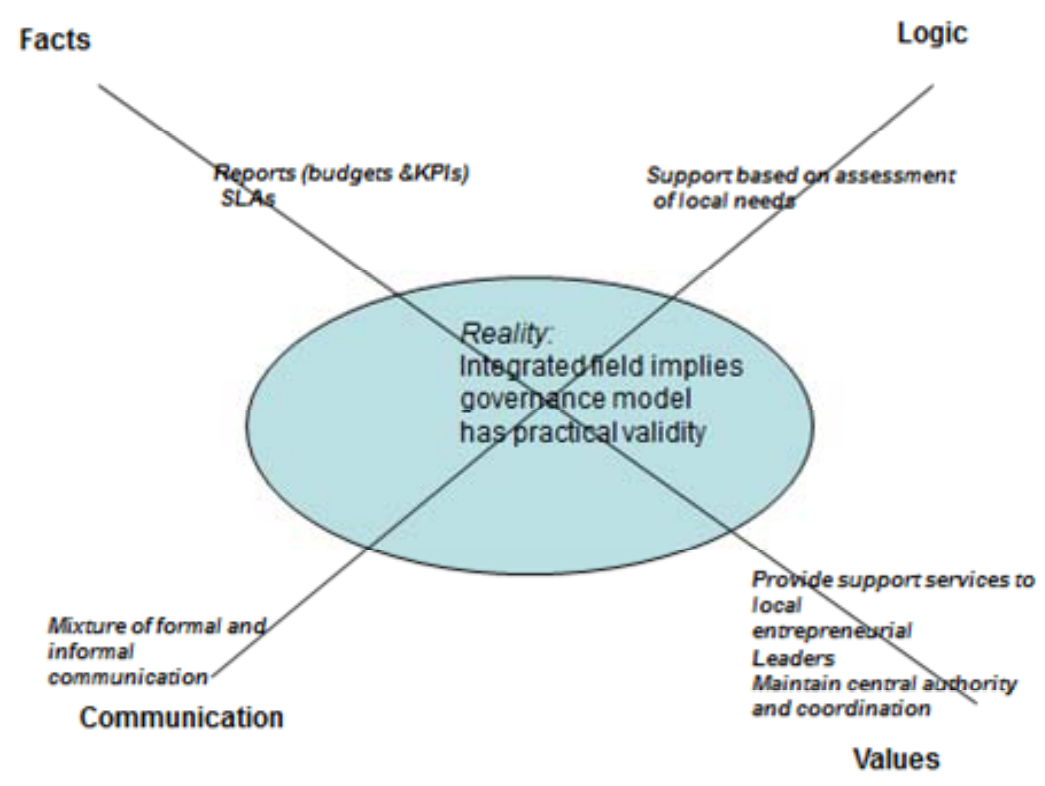

Figure 4. The SSO governance model and practical validity 


\section{Evaluating Trainco's captive SSO in terms of strategic management}

- if firms simply outsource their support services then they may face the danger that they represent an easily copied agency nexus of contract model (Teece, et al., 1997).

- if Trainco had chosen the usual SME model and outsourced its support services, it would have lost some of the non-replicable and idiosyncratic elements of its organizational capital.

- Trainco's decision to insource its support services created a unique and difficult to imitate governance model

\section{Conclusions}

- not claiming that the SSO model was the only/prime reason for Trainco's success but the SSO governance structure did support the firm's international growth and helped to consolidate the reputation of its brand.

- In terms of the PC model, the management control model at Trainco seemed to have the properties of practical validity. Actions were informed by organizational reality rather than illusions of control

- the SSO model of governance will not always have this quality but the small scale, bottom-up, organic and participatory culture at Trainco were the key features of this unusual application of the SSO model. 